\title{
Pathological and Histochemical Study on Mice Treated With Black Nightshade Solanum Nigrum L. and infected with Secondary Hydatid Disease
}

\author{
Nabeel E. Salih \\ Department of Biology \\ College of Education
}

Entisar R. Al-Kennany

Department of Pathology

College of Veterinary Medicine

Mosul University

\section{Received \\ 29/10/2006 \\ Accepted \\ 21/02/2007}

Buthaina H. Al-Sabawi

Department of Anatomy

College of Mosul Medicine

\section{الظلاصة}

تضمنت هذه الدرلسة معرفة التغيرات المرضية وكيمياء النسج في نسبج الكبد

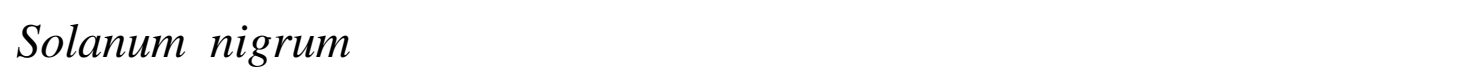

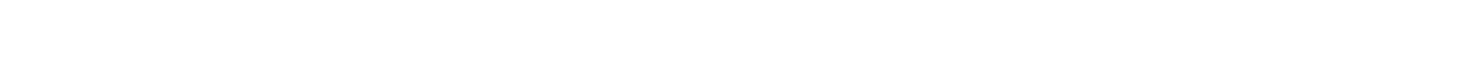

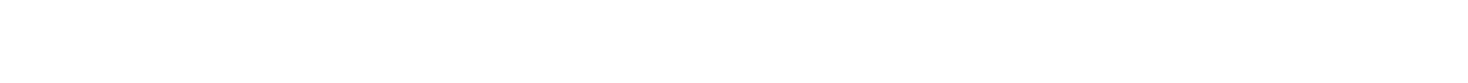

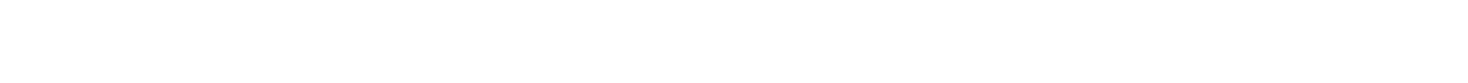

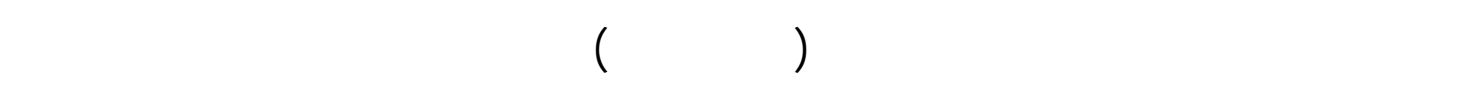
هذه التغيرات والدور الذي لعبه المستخلص النبلتي كمعل مناعي.

\begin{abstract}
Histopathological and histochemical changes in the liver and spleen tissues of mice which was treated with alcoholic extract of Solanum nigrum and infected with secondary hydatid disease, were investigated with an ultimate goal of determining the role which might be played by the extract in modulating the immune system towards a better response to the hydatid disease. Results demonstrate the appearance of hepatomegaly and splenomegaly due to deposition of amyloidosis in liver and spleen, in addition to other changes such as fatty changes and hemosiderosis. Causes of these changes and the role played by the plant extract, as an immunomodulator, were discussed.
\end{abstract}

\section{INTRODUCTION}

Cystic hydatid disease (CHD) caused by the larval stage of Echinococcus granulosus, is one of the most important zoonotic diseases in man (1). In addition to man more than 70 species of ungulates act as intermediate hosts for this parasite (2). Metacestodes develop in different organs of the body, causing dramatic damage dependent upon size and

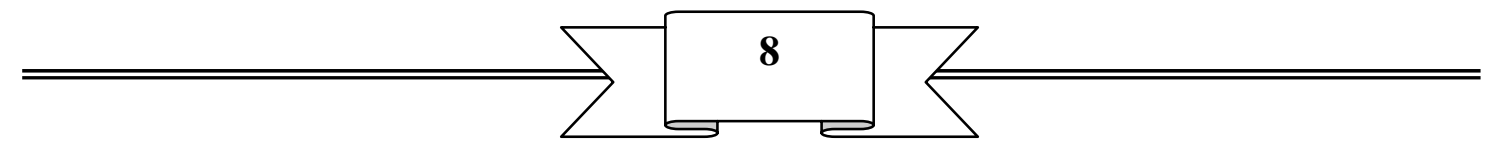


site of lesion in the organs (i.e. replacement of host tissue by growing cysts and in some instances, by vascular compromise). The main result of this development is the dysfunction of the organs in which cysts have grown. However, a clear picture on the histopathological changes which occur in infected hosts have been given by previous workers $(3,4)$. Among these studies, few only have focused on the histopathology of tissues in hosts infected with hydatid disease and treated with immunomodulators of different sources.

Although the pathogenicity of primary hydatid cysts is known, that of secondary hydatid disease, in which many cysts may well be established in the body due to the burst of a primary cyst or spillage of protoscoleces during operations, is not well understood, and an improvement of the immune response of the host towards secondary hydatidosis is needed.

The present work is, therefore, carried out to study the role which might be played by the alcoholic extract of the black nightshade Solanum nigrum which has been identified by Al-Sabawi (5) to play a role as an immunomodulator against the infection with secondary hydatid disease in altering the histopathology of liver and spleen tissues of mice treated with this extract and infected with secondary hydatid disease.

\section{MATERIALS AND METHODS}

Forty male, 3-4 weeks old, BALB/C mice, of the species Mus musculus, were used. Their weight ranged between 25-27 gm. They were divided into four groups (each with 10 mice). Group 1 (G1) is the control group (not infected with hydatid disease \& not inoculated with the plant extract). Group 2 (G2) was inoculated, intraperitoneally (ip), with alcoholic extract of plant leaves, which was prepared according to Rios et al. (6), it was inoculated into each mouse at a concentration of $0.3 \mathrm{mg} / 20$ gm body weight (5).

Mice were inoculated with the plant extract three times during the experiment period (three months at one-month interval). Group 3 (G3) was inoculated with the plant extract as in G2, then each was injected, intraperitoneally, with approximately 2000 protoscoleces of sheep origin. Isolation of protoscoleces from hydatid cysts was carried out according to Smyth (7). Viability test and preparation for inoculation was commenced according to Smyth and Barrett (8). Protoscleces with more than 90\% viability rate were used. Group 4 (G4) was injected with protoscoleces of sheep origin without treatment by the plant extract. 


\section{Dissection and tissue preparation}

Three months post infection, the mice were sacrificed. Secondary hydatid cysts were counted in the liver, spleen and peritoneum. Macroscopical changes were examined

Specimens from liver and spleen were fixed in 10\% neutral buffer formalin, processed routinely by alcohol and xylol and 4-6 $\mu$ thick sections were prepared and stained with hematoxylin-eosin stain.

The following histochemical techniques [listed below] with the appropriate controls, were undertaken according to Pears (9) : Periodic Acid Shiff (PAS), Acetylation- PAS, Saponification-PAS, Best Carmine (BC), Alician Blue (AB) pH 2.5, Methylation-AB pH 2.5, SaponificationMethylation-AB pH 2.5, AB pH 1.0, Toluidine Blue (TB) pH 4.0.

Chemical conversions were as follows

Acetylation (Acetic anhydride/pyridine) for $1.5 \mathrm{hr}$. Saponification (1\% $\mathrm{KOH}$ in $70 \%$ ethyl alcohol) for $20 \mathrm{~min}$. Methylation at $60^{\circ} \mathrm{C}$ for $4 \mathrm{hrs}$.

\section{RESULTS}

No histological changes were seen in the control group (G1) since all organs examined appeared normal in structure. In G2, hepatomegaly and splenomegaly were observed, in addition to severe congestion in both organs. When these organs were cut, by a knife, a waxy material, seems to be lipid in nature, was observed on the edge of the knife. In G3 and G4, white cysts, different in size, some with fluid (soft cysts), others without (solid) were observed.

\section{Histopathological Finding}

In G2, histopathological changes in the liver are represented by vacuolar degeneration, fatty change, dilatation of central veins, in addition to lymphocyte perivascular cuffing infiltration, with dilatation in the sinusoids and hypertrophied Kupffer cells (Figs. 1and 2).

In spleen, severe hemorrhage with deposition of hemosiderin, thickening in the walls of splenic arteries, in addition to amyloidosis (bacon spleen) occur around splenic follicles, and depletion in the center of this follicles, accompanied by substitution of the lymphocytes by plasma cells, were observed (Figs. 3 and 4).

In G3, in addition to the above-mentioned histopathological changes, some white cysts, containing fluid, different in size, were observed in the liver. They had germinal and laminated layers and were surrounded by the adventitious layer with large number of mononuclear cells infiltration (epithelioid, lymphocytes, macrophages, plasma cells and giant cells). Granulomatous lesions, characterized by containing necrotic and protoscoleces, which were surrounded by collagen fibers and 
large number of macrophages and epithelioid cells, in addition to foreign body giant cells (Figs. 5 and 6) were also seen.

In G4, many secondary hydatid cysts were observed in the liver, spleen and peritoneal cavity associated with a persistent congestion of blood vessels, atrophy of hepatocytes and Kupffer cells hypertrophied.

\section{Histochemical Finding}

Tables (1 and 2) show the reaction of the cyst wall and hepatcytes with different histochemical techniques. In G3, PAS technique showed a sever positive reaction with the germinal and laminated layers as well as hepatocytes, while in G4 the reaction was moderate.

Best Carmine technique showed a negative reaction with the laminated layer whereas a strong positive reaction appeared with the germinal layer in G3, in comparison with G4 where the reaction was moderately positive (Fig. 7).

Alcian Blue $(\mathrm{AB} \mathrm{pH} 2.5)$ showed a strongly positive reaction with the laminated layer, a moderate reaction with the germinal layer and a positive reaction with the hepatic cells in G3 \& G4. On the other hand, the reaction was negative after methylation but positive when saponification was followed by methylation. $\mathrm{AB} \mathrm{pH} 1.0$, showed negative reaction with the laminated layer and germinal layer in G3, in comparison with the G4 where it was positive reaction with the laminated layer and negative with germinal layer and hepatic cells (Fig. 8).

Toluidine blue (TB) showed a moderate change in color with the laminated layer and a negative reaction with the germinal layer and hepatic cells in G3 whereas the reaction was positive with both layers in G4 (Fig. 9).

\section{DISCUSSION}

Results of the present study demonstrate the occurrence of hepatomegaly and splenomegaly, resulting from amyloidosis in these organs, in addition to other changes such as fatty change and hemosiderosis. As these two organs represent a very important tissue of the reticuloendothelial system responsible for the immune response of the host, the ability of the plant extract to immunomodulate the non-specific immunity of the host, through stimulation of lymphocytic proliferation, induction of hypertrophy of Kupffer cells in the liver or may be due to liberation of tumor necrosis factor (TNF), a chemical mediator which stimulates the proliferation of lymphocytes. Appearance of amyloidosis in spleen may indicate the presence of hyperimmunoglobulinemia, namely arteriosclerosis, in addition to the fact that hydatid disease is a chronic disease accompanied by amyloidosis (10), which is a product of the immune complex formation which may result from the reaction of the 
cyst antigens with proteins like the complement leading to precipitation on the walls of the splenic blood vessels as eosinophlic homogenous material (Fig, 2) in the form of fibrils, or may result from the absence of the enzyme like serine esterase, which is responsible for the digestion of the fibrils, causing their precipitation on the blood vessel walls. The appearance of granulomatous lesions which revealed the host cellular defense that destroy the protoscoleces leading to stimulation of these lesions through liberation of chemical mediators. Plant extract seems to possess an ability to stimulate natural killing through stimulation of natural killer (NK) cells to proliferate. These cells are activated by lymphokines and interleukin-2 (IL-2) (these possibilities need more investigation).

As for histochemical findings, the results indicate the presence of more glycoproteins in the germinal layer, and a decrease in the mucopolysaccharide type sialomucine with a decrease in hyaluronic acid in the laminated layer in G4 compared with the G3. This may be due to the effect of the plant extract on the protoscoleces at the beginning of their invasion to the tissues and development to cysts. Carbohydrates are one of the main structural parts of the living cells, playing a role in the formation of other cell components such as proteins, lipids, nucleic acids, and other carbohydrates. Therefore, the plant extract seems to have caused a decrease in the glycogen and the mucopolysaccharide sialomucine in the germinal layer during growth and development of protoscoleces.

Results of the present study indicate the positive role played by the plant extract as an immunomodulator against secondary hydatid disease, as suggested by Al-Sabawi (5) and there is a need for further studies to demonstrate the factor (s) responsible for this role. 
Table (1). Histochemical reactions with hepatocytes, germinal and laminated layers of hydatid cyst in G3* mice.

\begin{tabular}{||l|l|l|l||}
\hline \hline Techniques stains & $\begin{array}{l}\text { Laminated } \\
\text { layer }\end{array}$ & $\begin{array}{l}\text { Germinal } \\
\text { layer }\end{array}$ & Hepatocytes \\
\hline \hline Periodic Acid Shiff (PAS) & ++++ & +++ & ++ \\
\hline Acetylation-PAS & - & - & - \\
\hline Acetylation-Saponification-PAS & ++++ & +++ & ++ \\
\hline Best Carmine & - & ++++ & ++ \\
\hline Alcian Blue(AB) pH 2.5 & +++ & ++ & + \\
\hline $\begin{array}{l}\text { Methylation AB pH 2.5 } \\
\text { Methylation-Saponification AB } \\
\text { pH 2.5 }\end{array}$ & - & - & - \\
\hline $\begin{array}{l}\text { AB pH 1.0 } \\
\text { Toluidine Blue (TB) pH 4.0 }\end{array}$ & - & ++ & + \\
\hline \hline
\end{tabular}

Table (2). Histochemical reactions with hepatocytes, germinal and laminated layers of hydatid cyst in G4** mice.

\begin{tabular}{||l|l|l|l||}
\hline Techniques stains & $\begin{array}{l}\text { Laminated } \\
\text { layer }\end{array}$ & $\begin{array}{l}\text { Germinal } \\
\text { layer }\end{array}$ & Hepatocytes \\
\hline \hline Periodic Acid Shiff (PAS) & +++ & ++ & + \\
\hline Acetylation-PAS & - & - & - \\
\hline Acetylation-Saponification-PAS & +++ & ++ & + \\
\hline Best Carmine & - & ++ & ++ \\
\hline Alcian Blue(AB) pH 2.5 & +++ & ++ & + \\
\hline Methylation AB pH 2.5 & - & - & - \\
\hline $\begin{array}{l}\text { Methylation-Saponification AB } \\
\text { pH 2.5 }\end{array}$ & ++ & ++ & + \\
\hline $\begin{array}{lll}\text { AB pH 1.0 } \\
\text { Toluidine Blue (TB) pH 4.0 }\end{array}$ & ++ & - & - \\
\hline \hline
\end{tabular}

* Group of mice inoculated with the plant extract, then each was injected intraperitoneally, with approximately 2000 protoscoleces of sheep origin.

** Group of mice was injected intraperitoneally, with approximately 2000 protoscoleces of sheep origin without treatment by the plant extract. 


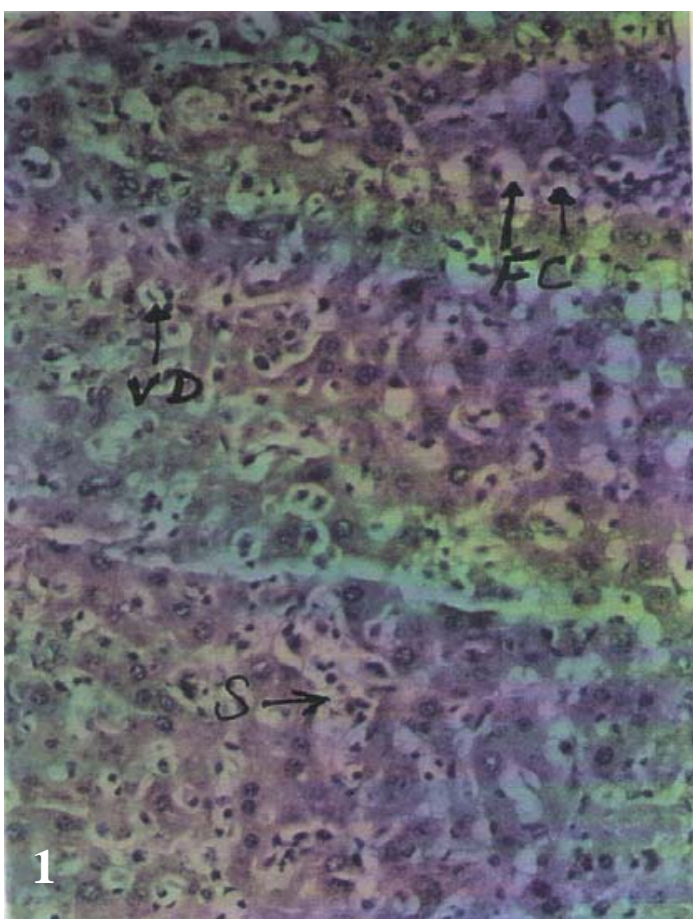

Fig. (1) Histomicrograph of liver in G2 (treated with alcoholic extract of Solanum nigrum), showing vascular degeneration (VD), fatty change (FC) and dilatation of sinusoids (S). H\&E. 400X.

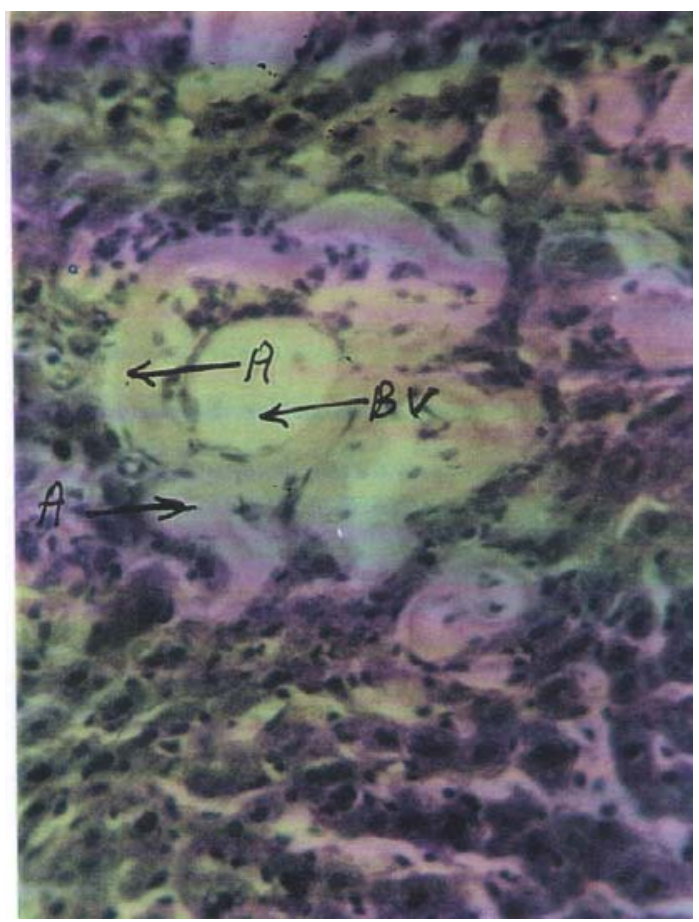

Fig. (2) Histomicrograph of liver in G2, showing deposition of amyloidosis(A) around blood vessels (BV). PAS. 400X. 

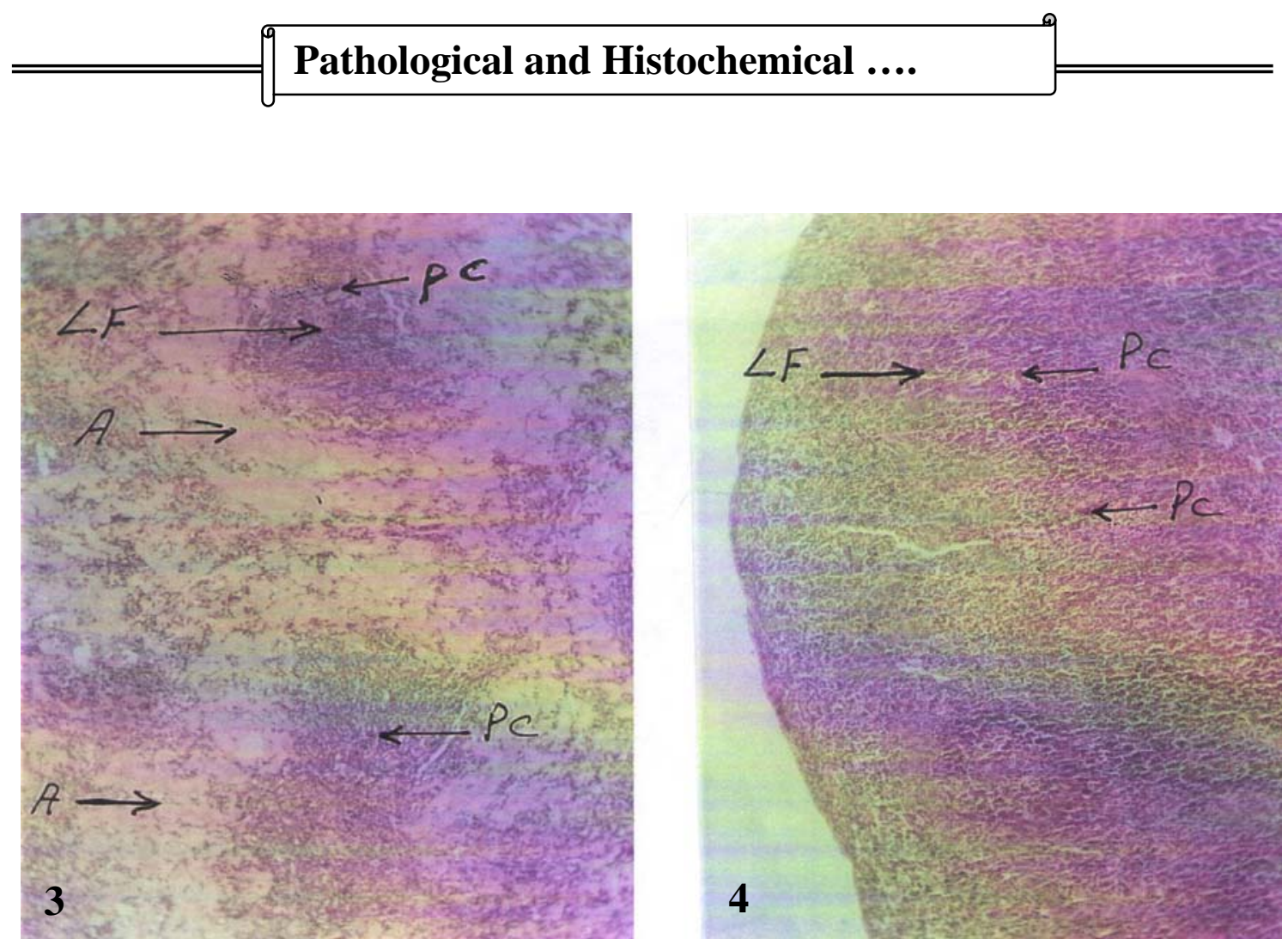

Figs. (3\&4) Histomicrograph of spleen in G2, showing deposition of amyloidosis (A) around lymphoid follicles (LF) and substitution of lymphocytes by plasma cells (PC). H \& E. 400X.

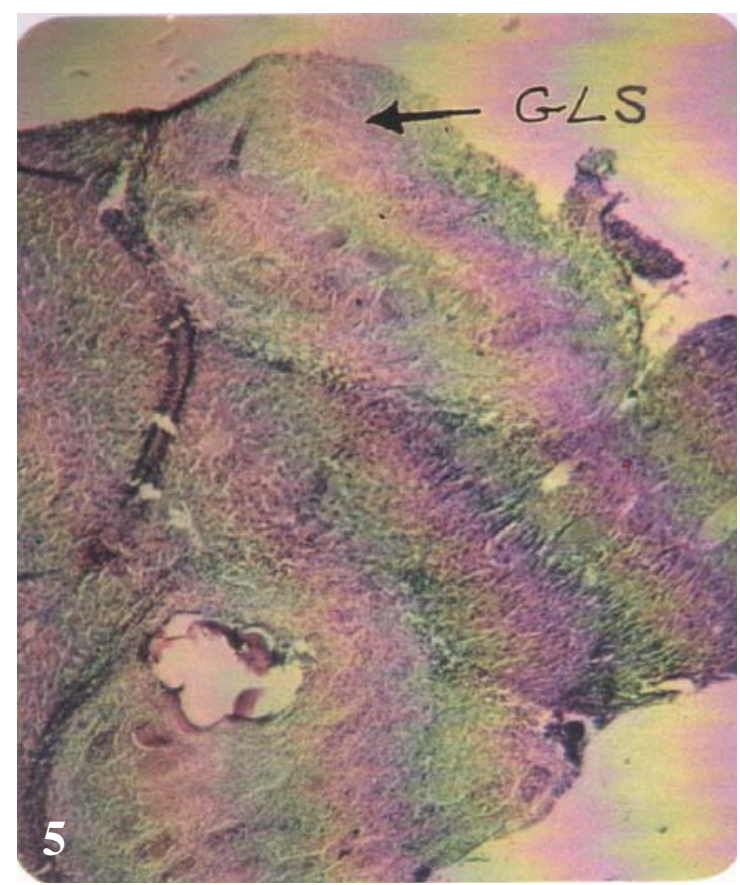

Fig. (5) Histomicrograph of liver in G3 (inoculated with the plant extract as in G2, then each was injected, intraperitoneally, with 2000 protoscoleces), showing granulomatous lesion (GLS) in the liver. PAS. 400X. 


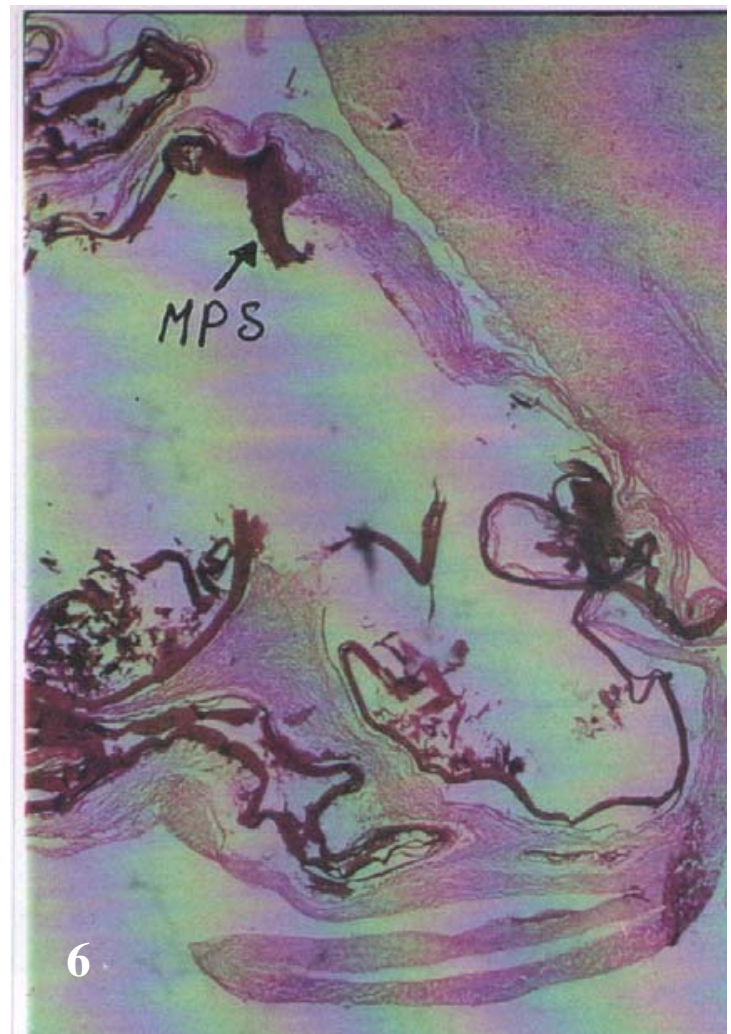

Fig. (6) Histomicrograph of liver in G4, showing positive reaction of PAS for mucoploysaccharides (MPS) with germinal (GL) and laminated layers (LL) as well as hepatocytes. PAS. 400X.

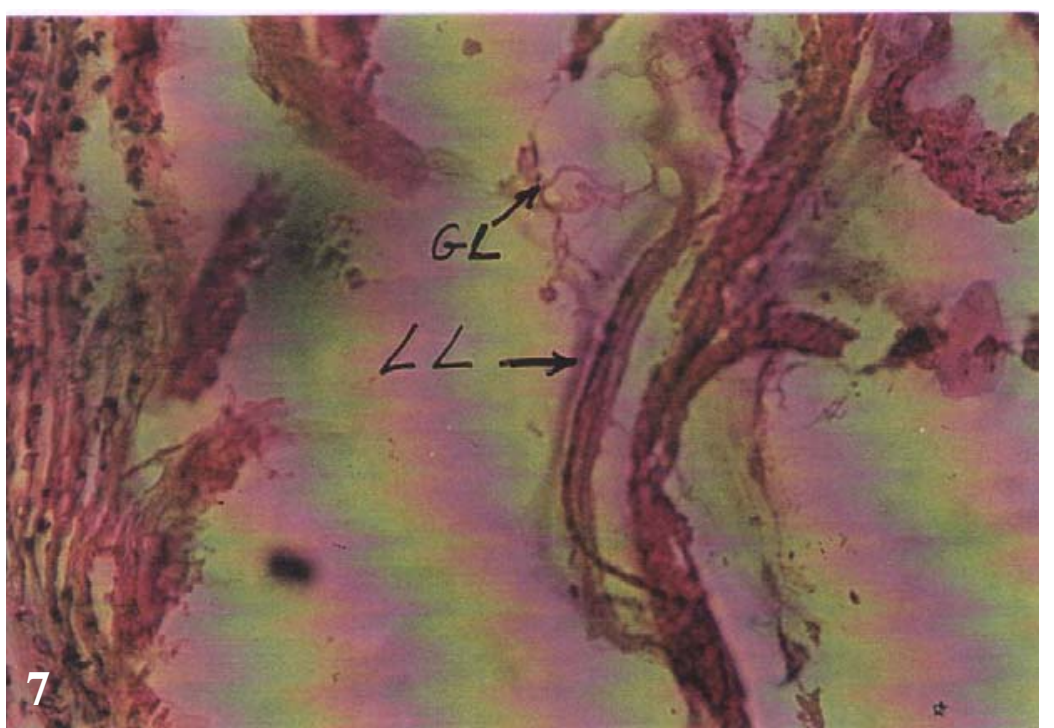

Fig. (7) Histomicrograph of liver in G4, showing negative reaction of BC with laminated layer (LL) but positive with germinal layer. 400X. 


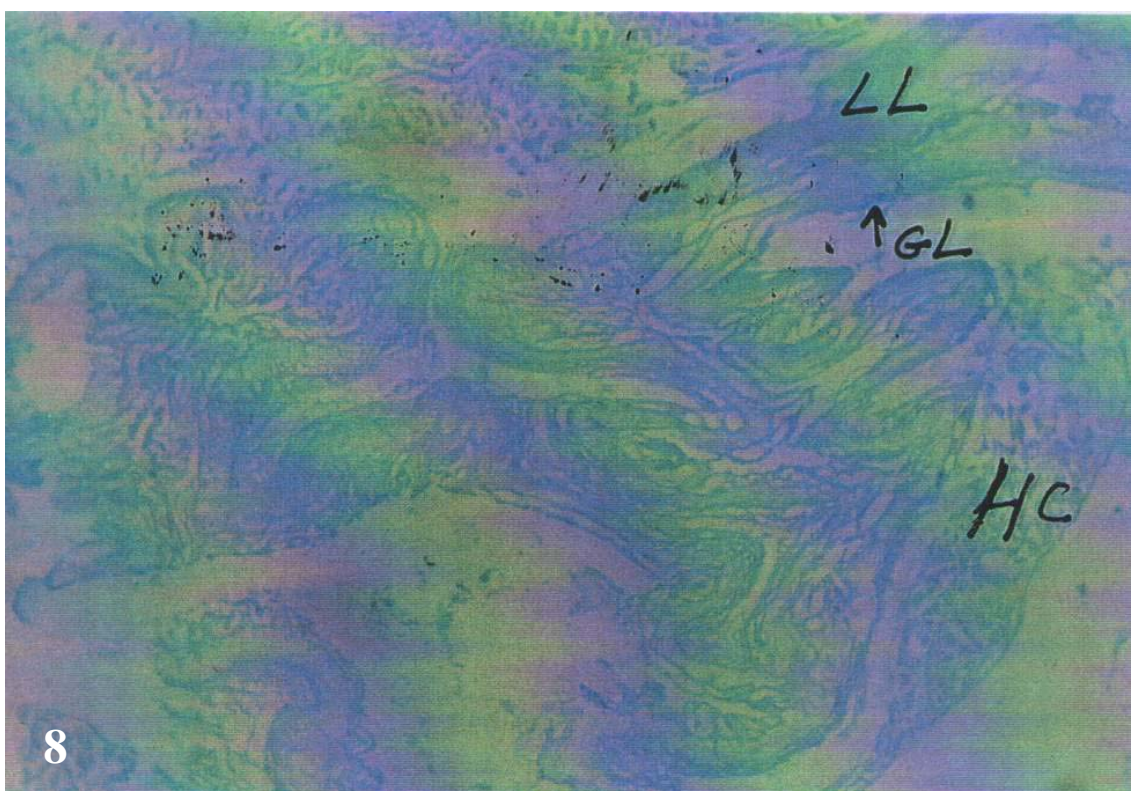

Fig. (8) Histomicrograph of liver in G4, showing negative reaction of AB pH1.0 with laminated layer (LL) but positive with germinal layer (GL) and hepatocytes (HC). 400X.

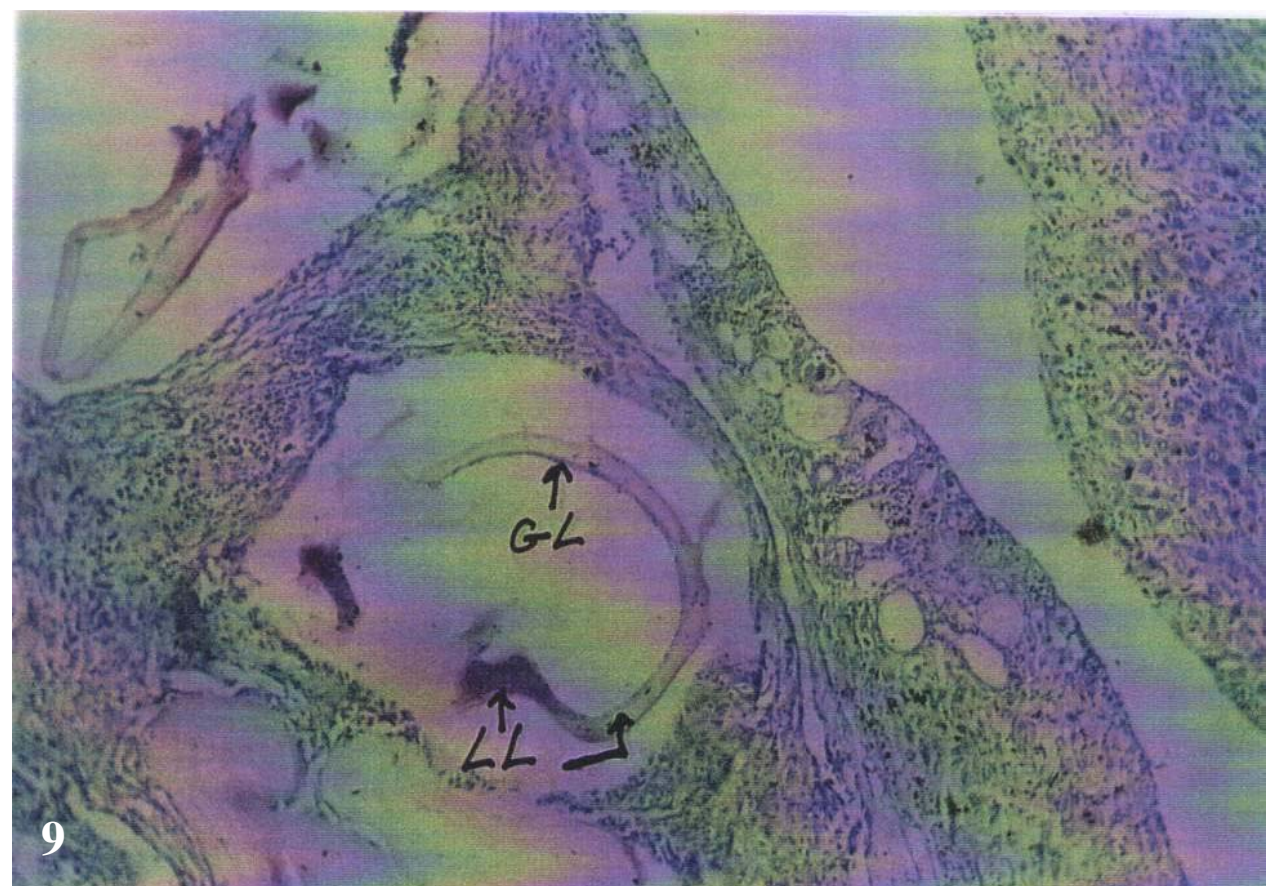

Fig. (9) Histomicrograph of liver in G3, showing positive color change in laminated layer but negative with germinal layer and hepatocytes using TB. 400X. 


\section{REFERENCES}

1- Andersen F.L., Ouhelli H. and Kachani M. " Compendium on Cystic Echinococcosis". Brigham Young University Print Services, UT 84604 (1997).

2-Smyth J.D., Changing concepts in the microecology, macroecology and epidemiology of hydatid disease: Geerts C, Kumar V, Brandt J (Eds.): Helminth Zoonoses. martinus Nijhoff Publishers (1987).

3-Ali, A.A. and Salih N.E., Riv. Parassit., XVII (LXI)-2:183-193 (2000a).

4-Ali, A.A. and N.E. Salih N.E., Riv. Parassit., XVII (LXI)-2: 195-202 (2000b).

5-Al-Sabawi B.H., Ph.D. Thesis, College of Science, University of Mosul (2001).

6-Rios, J.L., Recio M.C. and Villar A. J., Ethnopharmacol., 21: 139-159 (1987).

7-Smyth J.D. 1985., In vitro culture of Echinococcus spp. Proc. $13^{\text {th }}$. ed. Int. Cong.Hydatid, 84-95 (1985).

8-Smyth J.D.and Barett N.J., Trans.Roy. Soc. Trop. Med. Hyg., 74:649652 (1980).

9-Pears E., Histochemistry , Eoretical and applied. $4^{\text {th }}$. ed. London (1985).

10-Al-Kennany E.R.. Riv. Parassit., XIX(LXIII)-L: 29-38 (2002). 